\title{
A RAZOABILIDADE DA VONTADE EM DUNS ESCOTO
}

\author{
Gonçalo Figueiredo \\ Mestrando em Filosofia, FLUC
}

Agostinho Gemelli dá-nos um resumo cabal da vida de Escoto: "Não há talvez Doutor medieval mais incompreendido do que este franciscano escocês, que estudou em Oxford, ensinou em Paris, foi expulso por Filipe o Belo, morreu em Colónia na idade em que outros filósofos começam a produzir, como se a chama do pensamento lhe houvesse consumido a juventude. Até o próprio título de Doutor Subtil com que o distinguiram, tem uma aparência de ironia. Foi acusado de inovador e, entretanto, continua a mais antiga tradição escolástica, desenvolvendo as intuições de S. Agostinho e harmonizando-as, tanto quanto possível, com as de Aristóteles. Foi alcunhado de franciscano que perdeu o sentido do amor e no entanto a sua filosofia é toda fundada sobre o amor. Foi chamado "contraditor sistemático", "teólogo caviloso", "precursor" do voluntarismo e do imanentismo, de Kant do século XIII, e, em vez disso, o seu realismo é puramente escolástico, alheio a toda pretensa autonomia da natureza e do eu; e as suas teorias sobre Nossa Senhora e sobre a Encarnação recebem confirmação, séculos depois, no dogma da Imaculada Conceição e no culto a Cristo Rei ${ }^{1}$.

Procuramos neste estudo dar conta das nossas investigações sobre a vontade e liberdade em Duns Escoto, mais propriamente em Quodlibet XVI. Escolhemos este texto por nos parecer ser consensual entre os estudiosos a autenticidade das questões quodlibéticas atribuídas a Escoto, ainda que a edição crítica dos textos esteja por fazer. Aquela questão representa também, no nosso entender, um resumo da posição de Escoto sobre esta temática da liberdade, onde se joga a tensão entre o necessitarismo grego, rejeitado pelas condenações de 1277, e a fidelidade à tradição do pensamento cristão na linha de Agostinho e Anselmo, que procura manter intacta a absoluta liberdade do homem e do ser infinito.

1 GEMELLI, Agostinho, O Franciscanismo, Ed. Vozes, Petropólis 1944, 81.

Philosophica, 34, Lisboa, 2009, pp. 387-403 
Mais recentemente foi apresentada uma edição crítica $^{2}$ da questão que agora nos ocupa, e que nos servirá de base para a nossa apresentação. Usaremos a divisão e a numeração aí proposta que tem algumas diferenças da versão apresentada por Félix Alluntis ${ }^{3}$.

Disputada entre o Natal de 1306 e a Páscoa de 1307 na cidade de Paris, resume bem o pensamento do Doutor Subtil sobre a vontade. Pela morte prematura em 1308, não dispomos de mais desenvolvimentos deste autor sobre esta matéria. William Frank demonstrou uma unidade entre as questões 16 a 18 no que diz respeito a esta temática, sendo a primeira aquela que trata das possibilidades metafísicas da vontade, explicitando a linguagem e apresentando-se como ponto de partida para posteriores desenvolvimentos.

A Quodlibet XVI está dividida em três artigos, e apresenta uma unidade e completude que a permitem tratar por si mesma. Apresentaremos apenas alguns aspectos da questão que no âmbito deste colóquio nos parecem mais significativas.

A tese principal é afirmar que a vontade para ser verdadeiramente livre tem de ser razoável, ou seja, não se pode desligar da razão, tem de estar em conformidade com a recta razão.

\section{A inteligência como potência natural}

Com o primado da vontade, tocamos numa tese cara à Escola Franciscana $^{4}$. São Francisco e seus filhos sempre cantaram o amor acima de tudo, e deram à vontade, que o exprime, o papel mais nobre. João Duns Escoto não faz, em suma, senão reproduzir as intuições tradicionais da sua Ordem, quando estabelece com mestria o primado da vontade em filosofia, como porá o amor na base de toda a sua teologia.

Escoto dá à vontade primazia sobre a inteligência, sem que se veja obrigado a diminuir o papel da inteligência para exaltar o da vontade. A prioridade da origem cabe à inteligência, porque para querer é preciso primeiro saber: "O intelecto, porém, se é causa do querer, é causa subser-

2 NOONE, Timothy - ROBERTS, H. Francis, “John Duns Scotus' Quodlibet, a brief study of the manuscripts and an edition of question 16" in SCHABEL, Christopher, Theological Quodlibeta in the Middle Ages, Brill, Leiden-Boston 2007, 131-198.

3 ALLUNTIS, Félix, Obras del Doctor Sutil Juan Duns Escoto, Cuestiones Cuodlibetales, BAC, Madrid 1968.

4 A designação de "Escola Franciscana" é discutível. Alguns entendem-na em sentido mais lato de um conjunto de pensadores franciscanos, outros identificam um conjunto de temas, paradigmas e fontes que permitem, de facto, o uso deste termo. Veja-se RiBEIRo, Ilídio de Sousa, Escola Franciscana (História e Filosofia), Lisboa 1944, e Fraile, Guillermo, Historia de la Filosofia, BAC, Madrid 1940, vol. II, 741-753. 
viente da vontade, enquanto tem a primeira acção na ordem da geração; e este argumento conclui provavelmente a favor do primado da vontade e não do intelecto." 5

Sendo a inteligência como que a raiz antecedente da vontade, ela é essencialmente ordenada a um acto de vontade, de acção, o que faz notar a superioridade da vontade sobre a intelecção, que como o próprio Escoto afirma é "subserviente". Todavia, sendo condição indispensável para o acto de vontade, não é dele causa absoluta, pois a intelecção não produz a vontade como uma causa produz o seu efeito. A volição procede evidentemente da intelecção, que lhe fornece a sua matéria, mas a intelecção procede também da volição, que lhe regula o trabalho.

Afirma Escoto: "Que o intelecto não seja causa total da vontade é manifesto, porque, sendo a primeira intelecção causada por uma causa puramente natural e, sendo a intelecção não livre, do mesmo modo, o seguinte necessariamente causa o que causa, e do mesmo modo circular entre actos de intelecção e vontade, todo o processo é meramente de necessidade natural; o que é inconveniente, pois, para salvaguardar a liberdade do homem, é necessário afirmar que a pressuposta intelecção não tem a causa total da vontade, mas principalmente que a causa mais importante é a vontade, a qual, portanto, se pode dizer que é livre."6

De que modo a vontade pode ser causa parcial superior? Sendo uma a que manda e a outra a que é mandada, a superior é a vontade que manda a inteligência mandada.

A prioridade de origem cabe à inteligência, diz Escoto, porque para querer é preciso antes saber. Deve, pois, o conhecimento preceder todo o acto de vontade. $\mathrm{O}$ que redunda em dizer que a inteligência é a condição

5 Ord. II, d. 49, q. ex latere (Ed. Vivès, XXI): "Intellectus autem si est causa volitionis, est causa subserviens voluntati, tanquam habens actionem primam in ordine generationis; et ideo istud medium concludit probabiliter pro voluntate, pro intellectu nihil."

${ }^{6}$ Ord. II, d. 49, q. ex latere (Ed. Vivès, XXI): “Quod autem intellectio non sit totalis causa volitionis, patet, quia cum prima intellectio causetur a causa mere naturali, et intellectio sit non libera, ulterius simili necessitate causaret quidquid causaret, et sic, quomodocumque circuli fierent in actibus intellectus et voluntatis, totus processus esset mere necessitate naturali; quod cum sit inconveniens, ut salvetur libertas in homine, oportet dicere posita intellectione, non habere causam totalem volitionis, sed principaliorem respectu eius esse voluntatem quae sola libera est." É evidente que o intelecto não é a causa integral da vontade, porque, como a primeira intelecção é causada por uma causa meramente natural e a intelecção não é livre, por uma semelhante necessidade causaria, além disso, tudo aquilo que causa e, desta maneira, uma vez que teríamos uma circularidade nos actos do intelecto e da vontade, todo o processo seria meramente de necessidade natural; ora, dado que isto é inconsequente, a fim de salvarmos a liberdade no Homem, deve dizer-se que a referida intelecção não é a causa total da volição, mas que relativamente ao próprio ser a vontade, a única que é livre, é a causa principal. 
sine qua non da vontade; condição necessária e prévia. Necessária, porque sem conhecimento não há querer, precisando a vontade, como precisa, da inteligência para agir; prévia, porque o acto da inteligência vem antes do acto voluntário?.

A inteligência, sujeita ao domínio do seu objecto, e "movida necessariamente pelo objecto natural", acha-se por isso mesmo determinada do exterior; ao passo que, pelo contrário, a vontade se determina a si mesma $a b$ intrinseco. $\mathrm{O}$ papel da inteligência consiste em apresentar o objecto à vontade, mas não em inclinar a vontade a querê-lo.

Enquanto potência activa natural, mas racional, o apetite sensitivo está, por si mesmo, completamente determinado pelo conhecimento do seu objecto; ele não produz; é produzido, encontra-se determinado a actuar necessariamente. Além disso, "dado que é uma faculdade natural, este apetite não dispõe de nenhum meio para controlar-se a si mesmo, de modo que «naturalmente» dirige-se com toda a sua força ao seu objecto"9. O intelecto actua naturalmente, ou seja, conhece necessariamente os objectos para os quais se dirige a atenção, e isto aplica-se necessariamente a ambos os exercícios da acção e ao conteúdo da cognição. O entendimento humano está determinado pelo objecto inteligível ao que não pode negar-se a conhecer.

A explicação da diferença entre as potências irracionais e racionais como contraposição entre duas classes de princípios activos, a natureza e a vontade, é o modo como Escoto faz o aproveitamento da herança aristotélica. Segundo o adágio medieval: "Potentia rationalis velet ad opposita, irrationalis vero ad unum tantum", a distinção aristotélica entre potências racionais e potências irracionais deriva em Escoto na distinção entre natureza e vontade, onde o critério é ad opposita e ad unum. A inteligência ainda que esteja aberta a efeitos opostos não é capaz de determinar-se a si mesma sem que seja necessário algo exterior, é heterodeterminada ${ }^{10}$. O exemplo apresentado por Escoto é o sol que, podendo endurecer o barro ou derreter o gelo, para determinado objecto só pode agir de determinada maneira, e não de maneira oposta. Está determinada no sentido "em que

7 Cf. SAINT-MAURICE, Bérnard de, João Duns Escoto, Doutor dos tempos modernos, Ed. Vozes, Petropólis 1947, p. 189.

${ }^{8}$ Quodl., 27: "Et ratio differentiae est quia intellectus movetur ab obiecto naturali necessitate movente; voluntas autem libere se movet." O intelecto é movido pelo objecto natural que move necessariamente.

${ }^{9}$ Cf. GILSON, Étienne, Jean Duns Scot, Introduction a ses positions fondamentales, Librarie Philosophique Vrin, Paris 1952, 579.

10 Juan Duns Scoto, Naturaleza y voluntad, Quaestiones super libros Metaphysicorum Aristotelis, IX, q. 15, Introducción, traducción y notas de Crus González AYESTA, Cadernos de Anuario Filosófico, Univ. de Navarra, Pamplona 2007, 18. 
dadas as circunstâncias apropriadas, livre de obstáculos, ela necessariamente actua até ao seu limite."11

\section{Influência de Santo Anselmo}

Duns Escoto modela a sua própria teoria da vontade sobre a de Anselmo ${ }^{12}$. De acordo com o que encontramos nas referências de Escoto sobre a vontade como uma potência activa (comparável com o instrumento de Anselmo), a vontade é uma inclinação inata da potência (affectiones de Anselmo) e o acto de querer, ou seja, volição e nolição (o uso de instrumento, segundo Anselmo).

Um outro aspecto no qual Duns Escoto segue Anselmo envolve o significado da liberdade, embora em última análise haja uma crucial diferença. Para ambos os pensadores, a liberdade da vontade deriva da affectio iustitiae. O que isto significa para Anselmo é que alguém é livre na medida em que pode escapar à dependência dos seus desejos para o seu próprio benefício. Ele pode escapar enquanto seja capaz de pôr a sua

11 Marilyn McCord Adams, "Duns Scotus on the will as rational power", in Via Scoti, 840 .

12 FRANK, William, John Duns Scotus' Quodlibetal Teaching on the Will, 191-195. - Para a questão da dupla afeição da vontade veja-se ANSELMUS CANTUARENSIS, De casu Diaboli (os cap. 4, 13 e 14 são frequentemente citados por Escoto); é ainda em De concordia praescientia et praedestinationis et gratiae dei cum libero arbitrio, c. 9, que se encontra essa definição de afecção de justiça: "Voluntas utique dici videtur aequivoce tripliciter. Aliud est enim instrumentum volendi, aliud affectio instrumenti, aliud usus eiusdem instrumenti [...]. Affectio huius instrumenti est, qua si afficitur ipsum instrumentum ad volendum aliquid, etiam quando illud quod vult non cogitat, ut si venit in memoriam, aut statim aut suo tempore illud velit». - Sobre a origem anselmiana da distinção retomada por Escoto entre affectio commodi e affectio iustitiae ver principalmente NORMORE, C. G., «Picking and Choosing: Anselm and Ockham on the Choice» Vivarium 36 (1998) 23-39, onde Normore insiste sobre o facto de que há duas vontades segundo as quais o homem pode escolher: «the key element of Anselm's account to which I wish to direct your attention in his claim that an agent chooses by following one will rather than another» segundo Escoto, pelo contrário, não há duas vontades, mas dois afectos numa só vontade, se bem que a escolha suponha sempre dois afectos juntos, e não o jogo de oposição de afecção/vontade uma contra a outra. Veja-se do mesmo autor: "Anselm's Two Wills» em Les Philosophies morales et politiques au moyen Age, Actas do IX Congresso de Filosofia Medieval, 1995, pp. 759-766. Normore sublinha um aspecto muito importante que distingue radicalmente a posição de Escoto da de Anselmo: «the creature with one voluntas cannot become the creature with two by his own efforts». Segundo Anselmo, a affectio iustitiae deriva da graça enquanto que segundo Escoto a affectio iustitiae é da ordem da natureza, e define a própria natureza da vontade, a natureza livre da vontade. Cf. CREVELLON, Christophe, «L'affection de justice chez Duns Scot, Justice et luxure dans le péché de l'ange» in Duns Scot à Paris 1302-2002, Actes du colloque de Paris, 2-4 septembre 2002, Brepols 2004, 425-468. 
vontade ao serviço dos bens justos em vez das commoditates. Mais especificamente, o homem goza de livre vontade na medida em que pode servir a rectidão por ela mesma. Por justiça Anselmo parece querer dizer a ordem moral do universo fundado por Deus no começo da criação. A ordem da justiça obtém-se entre o homem e Deus, entre o homem e o homem, e entre o homem e as coisas. Além disso, esta ordem é expressão da suma justiça e suma bondade da vontade de Deus. A liberdade anselmiana é a capacidade, apoiada pela boa inclinação, de submeter a própria vontade à ordem divina das coisas, e por conseguinte, agir de acordo com ela.

Do mesmo modo, para Escoto, o homem goza da livre vontade precisamente porque ele é capaz de verificar a sua prossecução dos bens que são simplesmente para o seu benefício pessoal. Como ele apresenta, "esta afecção ... para a qual a justiça é a primeira influência moderadora da afecção para o que é para nosso benefício. Esta afecção pelo que é justo, digo, é a liberdade que é inata à vontade."13 Outra semelhança: a liberdade que se mostra ela mesma como negativa pela moderação do seu desejo por commoditates, no aspecto positivo, possibilita a vontade de se conformar com "a regra de justiça que recebeu da vontade que lhe é superior"14. O significado de justiça, contudo, não é tão fácil de determinar no caso de Escoto, embora ele distinga três tipos de justiça: infusa, adquirida e inata ${ }^{15}$.

\section{Vontade: appetitus cum ratione liber}

A vontade como potência que pode mover-se a si mesma da possibilidade para a actualidade sem qualquer outra causa directa, contradiz o axioma aristotélico de que tudo o que se move é movido por outrem (omne quod movetur ab alio movetur). É a ruptura com este fundamental

13 Ord. II, d. 6, q. 2, n. 49 (VIII, 49): "Illa igitur affectio iustitiae, quae est 'prima moderatrix affectionis commodi'... illa - inquam - 'affectio iustitiae' est libertas innata voluntati..."

14 Ord. II, d. 6, q. 2, n. 51 (VIII, 51) “... et ex quo potest moderari, tenetur moderari secundum regulam iustitiae, quae accipitur ex voluntate superior" Ibid., n. 60 (II, 55): “. .. boni in eliciendo actum, non utebantur voluntate secundum rationem eius imperfectam, in quantum scilicet est appetitus intellectivus tantum, agendo scilicet tali modo quo appeterent appetitu intellectivo agere, - sed utebantur voluntate secundum eius perfectam rationem (quae est libertas), agendo secundum voluntatem eo modo quo congruit agere libere in quantum liberum agit: hoc autem erat secundum regulam superioris voluntatis determantis, et hoc iuste."

15 Ord. II, d. 6, q. 2, n. 49 (VIII, 48): "Iustitia potest intelligi vel infusa (quae dicitur 'gratuita'), vel acquisita (quae dicitur 'moralis'), vel innata (quae est ipsamet libertas voluntatis)." 
princípio e a interpretação teleológica ${ }^{16}$ da vontade que permite a Escoto conceber a vontade como uma potência de livre auto-determinação ${ }^{17}$.

A definição escotista de vontade é "apetite racional livre" (Appetitus cum ratione liber ${ }^{18}$. Esse apetite é duplo por conseguinte, pois é natural e é livre. Natural, isto é, vontade em si; livre, ou seja, vontade na escolha. Só a vontade, embora nunca agindo sem motivos, já que, como acabamos de dizer, ela é um apetite racional, determina-se a si mesma, sejam quais forem os motivos, pois esse apetite racional é livre. Isto é tão verdadeiro que, apresentado o objecto à vontade pela inteligência, ainda quando esse objecto fosse irresistível, nem por isso a vontade fica menos regiamente livre, e mesmo então "age como senhora de si", e só adere à inteligência porque se determina a lhe aderir. É aqui o caso de citar o texto célebre de Santo Agostinho: "Nada está tanto no poder da vontade como a própria vontade" 19 . Considerada em si mesma, a vontade pende irresistivelmente para o seu objecto próprio, que é o bem; na escolha que fizer do bem, ela é perfeitamente livre ${ }^{20}$.

\section{Contingência da vontade}

Uma potência racional valet ad opposita enquanto é capaz de por si produzir actos contrários em relação ao mesmo objecto, ou seja, enquanto é capaz de auto-determinar-se a agir num sentido ou no seu contrário. Ser um princípio racional de acção significa ser capaz de auto-determinar-se no que diz respeito a actos opostos e não simplesmente a preferir objectos opostos. A autodeterminação implica a capacidade de actuar de modo oposto àquele em que agora actua, implica precisamente a noção de contingência. Assim pode dizer-se que ser um princípio racional é equivalente a ser uma causa contingente, «racional» significa para Escoto «contingente». E há uma única causa contingente e uma só potência racional: a vontade, que é uma causa contingente, livre e natural.

Escoto considera que a vontade, como potência racional, está caracterizada por duas notas: autodeterminação e contingência. $\mathrm{O}$ nosso autor caracteriza a capacidade da vontade de actuar a respeito dos opostos,

16 Quodl. XVI, 25.

17 WILliams, T., The Cambridge Companion to Duns Scotus, 323-325.

18 Ord. III, d. 17, q. un., n. 2; cf. Ord. III, d. 33, q. un., n. 9: "appetitus racionalis"; Rep. II, d. 25, q. un., n. 19: "appetitus intellectivus".

19 AUGUST. Retract., I, 22, 3 (PL 32, 620): "nihil tam in potestate quam ipsa voluntas est". ANSELM. De conceptu virginali et originali peccato, 4 e 8. Ord. II, 25, q. un, n.2. cf. Quodl, XVI, 19.

20 BERTONI, Efrem, Duns Scot Filosofo, Società Editrice Vita e Pensiero, Milano $1966,179$. 
tanto de maneira positiva (autodeterminação) como negativa (indeterminação) ${ }^{21}$.

A vontade é um princípio activo que causa os seus efeitos de modo contingente e é, por isso, a raiz de toda a contingência. Esta contingência deve entender-se como a capacidade de agir de um modo distinto daquele com que age no momento em que está a agir, e não simplesmente como uma contingência que resulta do mundo natural pela concorrência de duas séries causais. A capacidade de uma potência escolher, por si mesma, actos opostos é própria da vontade como causa contingente.

Contingência diacrónica de em momento diferentes escolher diferentes coisas, e contingência sincrónica ou do presente que é a capacidade de no mesmo momento em que escolhe poder escolher algo diferente. É falso que ao mesmo tempo a vontade queira e não queira a mesma coisa, é verdade que a vontade pode querer em momentos diferentes coisas opostas. Mas quando a vontade quer alguma coisa num determinado momento, mantém nesse mesmo instante a capacidade de não o querer. Esta proposição é verdadeira e permite explicar a abertura da vontade aos opostos no momento da sua acção. Quando a vontade quer um objecto, ela tem o poder real de não querê-lo no mesmo instante em que o quer. Por isso é contingente não só antes de exercer o seu acto, mas no mesmo momento em que está a exercer o seu acto, assim se entende a contingência sincrónica.

A vontade é livre precisamente quando causa e por isso pode estar relacionada com os seus actos de um modo contingente no mesmo momento em que causa e não só no momento prévio a causar.

A vontade como toda a potência é anterior ao seu acto não em ordem cronológica mas por natureza. Logo a vontade é capaz de querer o contrário do que quer não só considerado em si o instante temporal anterior, nem tampouco considerada actualmente com o seu acto, mas considerada como anterior por natureza ao seu acto. Esta prioridade permite estabelecer uma duplicidade de instante de natureza num mesmo instante temporal.

${ }^{21}$ Quaestiones super libros Metaphysicorum, IX, q.15, n. 43: “a vontade não é por si princípio determinado a respeito das suas acções, seja no que se refere a um ou a outro dos opostos, mas pode determinar-se a qualquer deles."

Quaestiones super libros Metaphysicorum, IX, q.15, n. 43: "Só há dois modos genéricos de escolher a própria operação. Pois ou uma potência está em si mesmo determinada a agir de tal maneira que por si mesma não pode deixar de agir assim se não é impedida desde fora. Ou não está determinada por si mesma, mas que pode fazer este acto ou o seu oposto; agir ou não agir. O primeiro tipo de potência chama-se comummente "natureza" e o segundo chama-se "vontade". 


\section{Indeterminação da vontade}

A vontade humana, pela sua essencial indeterminação, encerra em si a possibilidade de poder realizar actos volitivos opostos e, por meio de actos opostos, tender livremente para objectos, seja de uma maneira imediata seja movida por outras potências executoras ${ }^{22}$. Nisto consiste a liberdade da vontade, pela sua indeterminação, possui a possibilidade de autodeterminar-se e querer o contrário ou não querer.

Mas a vontade é, em si mesma, indeterminada, o que significa que a opção por actuar não é única e necessária, mas múltipla e contingente: "pode realizar este acto volitivo ou o seu contrário e tender a este objecto ou ao seu contrário ou não querer nenhuma das opções contrapostas, ou seja, pode amar ou odiar um mesmo objecto, ou mesmo ser indiferente diante desse objecto"23.

A indeterminação essencial da vontade humana é a causa da possibilidade dos seres livres, ainda que essa liberdade não seja absolutamente perfeita, como tudo o que é humano e criado, ela encerra em si também imperfeições. Ela está condicionada por actos concretos que executa e por objectos a que o acto tenda. Pelos actos da vontade os objectos são queridos de modo contingente, a vontade que agora quer determinada coisa, pode, no instante seguinte, não a querer, ou querer o contrário, "a imperfeição da vontade humana pela qual quer e tende sucessivamente a objectos opostos, é consequência da sua mutabilidade. (...) Todo o objecto querido livremente pela vontade humana é querido de uma maneira contingente, e, em consequência, pode deixar de ser querido pela vontade para passar esta a querer outro objecto distinto, também de uma maneira contingente. Contingência e possibilidade são qualidades que acompanham os actos e os objectos queridos pela vontade livre do homem e são consequência da sua radical indeterminação e mutabilidade." 24

Como pode alguém ao mesmo tempo ter capacidade para $\mathrm{X}$ e para o

22 Cf. Juan Duns Scoto, Naturaleza y voluntad, Quaestiones super libros Metaphysicorum Aristotelis, $I X, q .15$, Introducción, traducción y notas de Crus González AYESTA, Cadernos de Anuario Filosófico, Univ. de Navarra, Pamplona 2007; Lectura I, d. 39, q. 1-5, n. 45 (XVII, 493): "voluntas enim nostra libera est ad actus oppositos (ut ad volendum, et nolendum, et amandum et odiandum), et secundo mediantibus actibus oppositis est libera ad objecta opposita ut libere tendat in ea, et tercio est libera ad effectus quos producit seve immediate sive alias potentias exsecutivas".

23 PÉREZ-EstÉVEZ, Antonio, "Liberdade divina, possibilidad y contingência en Duns Escoto", in Veritas 50(2005)3, 86.

24 PÉREZ-ESTÉVEZ, Antonio, "Liberdade divina, possibilidad y contingência en Duns Escoto", in Veritas 50(2005)3, 87. 
seu contraditório (não X) ou para o seu contrário Y? A vontade é por si mesma autodeterminação para opostos (quer contraditórios quer contrários), pois é uma potência que não está exaustivamente constituída por qualquer tendência, ou tendências em função de um objecto, é a característica da sua indeterminação. Antes tem o poder para agir ou não agir referente ao objecto e agir de modos contrários, e por isso é capaz de actos contrários de querer (velle) e não querer (nolle) ${ }^{25}$.

Uma vez que o estatuto da vontade, como uma potência voluntária, é constituído por ser uma autodeterminação de poder para opostos ou contrários em contradição, e por isso é naturalmente prévio à identificação das suas afeições, tal capacidade para opostos não deve ser derivada da dupla inclinação. Parece, pelo contrário, que esta distinta capacidade por opostos deveria afectar cada afeição, tomada em separado. Além disso, o poder da vontade para contraditórios opostos deveria incluir, por um lado, o poder de querer ou não querer alguma vantagem, não querer ou não não querer algo desvantajoso, por outro lado o poder de querer ou não querer um intrínseco bem por si mesmo, não querer ou não não querer qualquer injustiça. Do mesmo modo, a affectio commodi por si mesma deveria ser uma tendência em ordem a bens incompossíveis.

Não assim no Ser Infinito que quer necessariamente tudo o que quer ${ }^{26}$. Para o teólogo franciscano a vontade é uma perfeição pura que se encontra em Deus na sua plenitude e qual amor forma a essência; por isso Deus ama-se necessariamente a si próprio, mas nesta necessidade brilha a suprema liberdade da vontade que é sempre rationabilissime et ordinatissime volens ${ }^{27}$, pelo que não pode não querer o próprio ser infinito, enquanto o universo dos entes infinitos provém da sua livre escolha racional e ordenada entre os infinitos mundos possíveis, nunca irracional ou arbitrária.

Deus é essencialmente amor, e também o homem, criado à sua imagem, é ontologicamente constituído na sua raiz por um chamamento ao amor; segundo Duns Escoto, mais que a inteligência, o núcleo essencial da pessoa consiste na vontade com a qual livremente se orienta a si própria e em seguir o amor fontal. ${ }^{28}$

A razão prende-se com a busca do fim deleitável, querido pela sua bondade, que atrai para si. Uma razão que não tenda para esse fim não é uma razão liberta, mas escrava do pecado. Poder pecar é diferente de não poder pecar e também diferente de poder não pecar. Trata-se da questão

25 Cf. ADAMS, Marilyn McCord, "Duns Scotus on the will as rational power".

${ }^{26}$ Quodl. XVI, 31: "Deus necessario vult quidquid vult".

27 Ord., III, d. 3, q. un, n. 6.

28 Ord., I d. 2, p. 1, qq. 1-2, n. 75-110; d. 10, q. un; Rep. par., IV, d. 49, qq. 1-4; Quodl. XVI, 22 
quanto a Deus, ser infinito, sumamente amável, e quanto ao homem na sua actual condição, enquanto viator. A antropologia de Escoto é significativa e apresenta traços distintivos e de grande alcance na compreensão do ser do homem na sua situação presente de ser relacional.

\section{A dupla afeição}

Indo buscar a sua inspiração a Anselmo, Escoto assinala na vontade uma dupla nativa afeição pelo bem: a afeição commodi, que inclina a vontade a querer o bem enquanto está ordenado ao agente, ou seja, para a perfeição própria do agente, e a afeição iustitiae, que inclina a vontade para a intrínseca bondade das coisas, por elas mesmas, para além de serem ou não em beneficio do agente. Contrariamente a Anselmo, Escoto insiste que nenhum dos afectos é superior à vontade, mas ambas lhe são essenciais e intrínsecas. Ambas as afeições contribuem para definir o próprio objecto pelo qual a vontade é uma potência. Conformidade, vantagem e justiça devem ser aspectos que fornecem ao agente razões para querer alguma coisa, enquanto que desvantagem e injustiça são razões para não querer.

Isto não leva Escoto a dizer que nós podemos querer o que é de re vantajoso, somente em virtude de ter a affectio commodi. Uma vez que o agente, como outro qualquer ser, tem valor intrínseco, a sua preservação e florescimento devem assim ser incluídos entre os objectos para os quais a affectio iustitiae se incline. Inversamente, a affectio commodi pode inclinar a efeitos justos, onde a justiça e o vantajoso convergem. Mas ausente uma ou outra afeição, a vontade não seria a potência de querer ou não querer determinado objecto sob tal aspecto ou por essa razão.

\section{Affectio commodi}

Referindo-se a Anselmo, Escoto argumenta que a vontade tem duas possibilidades de se dirigir para o bem. Uma é a afeição pelo que é vantajoso (affectio commodi) o que corresponde aproximadamente com a descrição de natureza, correspondendo ao apetite intelectual, tal como é entendido na psicologia natural. Ela inclina o homem à sua perfeição e felicidade em tudo o que faz. Se fosse só esta a tendência operativa, amaríamos Deus apenas porque ele é o maior bem e a própria perfeição do homem, seria o supremo objecto do amor humano.

A affectio commodi é a inclinação que a vontade, enquanto desejo, de amar ou querer uma coisa, na medida em que constitui um bem para mim (bonnum mihi), ou seja, não tanto que a coisa seja boa em si mesma, segundo o seu valor intrínseco, mas enquanto ela é um bem por outra 
coisa além dela mesma (propter aliud). A affectio commodi da vontade segue então segundo a lógica do desejo (eu não desejo uma coisa em função de um desejável que é desejado por mim e para mim mais do que o desejo é uma falta de ser que procura a sua completude, e no amor o mais forte que se leva ao outro, é todavia o meu bem, o meu comprazimento, que eu procuro através desse amor $)^{29}$.

\section{Affectio iustitiae}

Há uma segunda e mais nobre tendência na vontade, uma inclinação ou afecto pela justiça, assim chamado porque inclina para fazer justiça ao bem objectivo, ao intrínseco bem da coisa, sem atender a sua felicidade de ser um bem para si mesmo ou não. Significativamente, tal como Anselmo antes de Escoto, ele insiste em que a affectio iustitiae (a capacidade inclinação para amar as coisas pelo seu valor intrínseco) é mais nobre que a affectio commodi (a inclinação capacidade para amar as coisas enquanto elas beneficiam o próprio) ${ }^{30}$.

A affectio iustitiae é constitutiva e inseparável da vontade e tem várias interpretações: 1$)$ a que inclina a amar uma coisa primeiramente pelo que ela é, ou tem, em si mesma (o seu valor absoluto) mais do que o que possa ser para nós (valor relativo), amar a coisa por si mesma; 2) consequentemente, o afecto pela justiça leva a amar a Deus por Ele mesmo como o mais perfeito e adorável dos objectos; 3) permite ainda amar o próximo literalmente por ele mesmo; 4) um amor que não é invejoso do amado, mas procura fazer o melhor e o mais apreciado pelos outros. Esta afeição pelo que é justo, que é a primeira influência moderadora da afeição para o que é vantajoso. Assim se vê que esta afeição é mais do que a capacidade de contradição ou de contrariedade. Não é a questão da escolha livre, mas escolher melhor segundo a recta razão. É esta afeição que representa a diferença específica da vontade.

Pelo facto de ser capaz de temperar ou controlar a inclinação para o que é vantajoso, segue-se que se obriga a agir de acordo com a regra da justiça que recebe de uma vontade superior. Se o homem não tivesse vontade livre, mas apenas um apetite intelectual, seria regulado exclusivamente pela inclinação para o que é vantajoso e seria incapaz de pecar. Do mesmo modo, o comportamento moral seria também impossível. Por outro lado, se a liberdade da vontade significasse nada mais que a simples inclinação do apetecer, as suas acções seriam irracionais, no sentido pejo-

29 CREVELLON, Christophe, «L'affection de justice chez Duns Scot, Justice et luxure dans le péché de l'ange».

30 cf. Marilyn McCord Adams, "Duns Scotus on the will as rational power”, 845. 
rativo do termo, sendo governado por capricho ou pelo acaso. O que é preciso é um contrapeso que liberte o homem de seguir a affectio commodi exclusivamente e estar de acordo com a recta razão.

Uma vontade dotada com affectio iustitiae já não é meramente passiva ou simplesmente resposta, como o apetite intelectual, e a affectio iustitiae permite-nos querer livremente o que é moralmente requerido sem considerar a felicidade, de tal modo que possamos escolher actos moralmente bons. Pode-se chamar a este aspecto da liberdade "liberdade moral". Mas a concepção de liberdade de Escoto tem outro aspecto, que se pode chamar "liberdade metafísica"; e não é de todo claro como a liberdade metafísica e a liberdade moral se compaginam.

Há razões para retrair ou moderar o apetite intelectual sempre que procura a felicidade, se descontrolado será imoral, ou noutras palavras, será contrário à vontade divina. De acordo com Escoto, o anjo rebelde pecou a primeira vez por querer a própria felicidade de um modo que Deus tinha proibido. Porque Deus tinha querido que eles tivessem retraído a sua affectio commodi, eles podiam fazê-lo; porque tinham uma affectio iustitiae, eles estavam capazes de o fazer, e por isso foram censurados quando o recusaram a fazer. A vontade de Deus é, de facto, a regra ou padrão para todo o apetite livre.

Um apetite livre é recto em virtude do facto de querer o que Deus quer que se queira. Assim, essas duas afeições, a affectio commodi e a affectio iustitiae, são reguladas por uma regra superior, que é a vontade divina, e nenhuma delas é regra para a outra. E porque a affectio commodi por si mesma pode ser imoderada, a affectio iustitiae é o limite para a moderar, porque é limitado por uma regra superior, e essa regra quer que a affectio commodi seja moderada pela affectio iustitiae ${ }^{31}$.

Escoto refere-se a Anselmo, De casu diaboli, onde se expressa a dupla inclinação. Um anjo que seja capaz de querer e não querer alguma coisa, e manter-se no que quer, não teria motivo para querer uma coisa em particular mas o bem absoluto.

Anselmo considera que se Deus criasse um anjo apenas com uma genérica vontade para $F$, o anjo não seria senhor dos seus actos, porque desejaria apenas F por necessidade natural, e receberia o seu querer de outro distinto dele, isto é, de Deus. Assim, se um anjo tivesse somente a affectio iustitiae, ele quereria a justiça por natural necessidade e por isso não seria justo apesar dos seus actos. Somente um agente voluntário, uma potência racional, poderia possuir uma afeição de justiça. Se a vontade criada fosse constituída somente pela affectio commodi de tal modo que fosse um mero apetite intelectual, inevitavelmente quereria o aparente máximo vantajoso para si. Quando Escoto identifica a affectio iustitiae

31 Rept., II, d. 6, q. 2, n. 10. 
como a primeira identificação na persecução da vontade da sua individualidade ou especial vantagem, isto não é porque ele pense que as duas afeições por si mesmas fossem suficientes para fazer a vontade senhora dos seus próprios actos, mas porque entende que a affectio iustitiae inclua o excelente poder de autodeterminação como sua necessária pré-condição.

Nobreza da vontade: Utrum potentia sit nobilior, intellectus an voluntas? ? $^{32}$

Para Escoto não é tanto o entendimento racional que caracteriza o ser humano e o distingue da natureza, na linha da tradição aristotélico-tomista, mas a potência ou faculdade activa volitiva. É a vontade que distingue essencialmente o homem do mundo natural e nos faz semelhantes a Deus, dando-nos a capacidade de sermos livres, isto é, de escolher ou de querer actos contrários que possam conduzir a objectos contrários ou simplesmente não querer nenhum objecto.

Intelecto e vontade são as duas potências emergentes da memoria sui que exprimem a natureza própria do sujeito humano. Duas faculdades racionais da alma, mas enquanto a primeira age de modo natural, isto é, determinado ao objecto, a outra, ao invés, age de modo livre (appetitus cum ratione liber); sendo de todo indeterminada, ela pode agir ou não agir, ou agir em sentido contrário: a escolha ou a recusa, mesmo diante do sumo bem, dependendo exclusivamente de si, e isto simplesmente quia voluntas est voluntas, não necessita de nada extrínseco a ela ${ }^{33}$. O nosso filósofo acentua fortemente o contraste entre aquilo que é natural e aquilo que é voluntário; para ele, de facto, a liberdade não é oposta à necessidade, mas à natureza, isto é, à causa determinante.

Ora a vontade pode autodeterminar-se a fazer o contrário, a inteligência ao contrário é orientada numa só direcção; a causalidade da vontade, portanto, goza de uma flexibilidade racional muito maior do que aquela do apetite sensitivo ou da faculdade da inteligência ${ }^{34}$.

Se a vontade, isto é, o poder pelo qual se escolhem e iniciam acções, é meramente apetite intelectual, então a vontade não seria mais que uma resposta passiva a qualquer razão que se apresentasse como bem. A questão volta-se assim para a escolha do bem e a compreensão de alguma

32 Ord. II, d. 49, q. ex latere (Ed. Vivès XXI). ToDISCO, Orlando, Giovanni Duns Scoto, Filosofo della libertà, Ed. Messaggero di S. Antonio, Padova 1996, 178-180 .

33 Cf. Quaest. super libros Metaphysicorum Aristotelis, IX, q. 15, nn 20-41; Rep., II, d. 25 , q. un, n. 20

34 Cf. PopPI, A., "Duns Scoto" in Enciclopedia Filosófica, 3151-3152. 
coisa como bem, e por isso desejável. Há na vontade, segundo Escoto, uma dupla inclinação da vontade, a affectio commodi e a affectio iustitiae. A affectio commodi corresponde ao apetite intelectual como é entendido na psicologia natural. A affectio iustitiae, mais difícil de caracterizar, é o que possibilita à vontade a liberdade que não poderia ter se fosse um mero apetite intelectual; é o que distingue um apetite livre de um apetite não livre, "última diferença específica de um apetite livre".

Entre o intelectualismo e o voluntarismo, Escoto esboça uma terceira via: um terceiro meio deduzido da comparação entre os actos da vontade e os do intelecto. E conclui: "Que o intelecto não seja causa total da vontade é manifesto, porque, sendo a primeira intelecção causada de uma causa puramente natural e, sendo a intelecção não livre, do mesmo modo, o seguinte necessariamente causa o que causa, e do mesmo modo circular entre actos de intelecção e vontade, todo o processo é meramente de necessidade natural; o que é inconveniente, pois, para salvaguardar a liberdade do homem, é necessário afirmar que a pressuposta intelecção não tem a causa total da vontade, mas principalmente que a causa mais importante é a vontade, a qual, portanto, se pode dizer que é livre" 35 . Na sua via media $^{36}$ entre o suposto voluntarismo de Henrique de Gand e o intelectualismo extremo de Godefroid de Fontaines, o Doutor Subtil propõe uma solução de co-causalidade parcial e eficiente, onde o objecto comum e a vontade juntos desempenham um papel importante no acto da vontade ${ }^{37}$. Esta via é talvez uma posição mais intelectualista que voluntarista, no sentido em que a razão se identifica com o intelecto e a liberdade com a vontade. Mas, sem dúvida que a superioridade da vontade encontra-se na liberdade e no controlo que ela exerce sobre o intelecto.

\section{Em suma:}

A vontade segundo Escoto não é só um apetite ou tendência intelectual que, como todo o apetite ou tendência natural, não pode senão buscar no outro a realização do próprio bem, com uma liberdade limitada a escolher um bem parcial, segundo o aspecto que o intelecto lhe apresente. A liberdade é razoável e livre em si mesma e por si mesma. Como razoável, é capaz de ver a diferença entre o bem relativo da sua tendência natural,

35 Ord. II, d. 49, q. ex latere (Ed. Vivès, XXI).

36 "Ideo teneo viam mediam, quod tam voluntas quam obiectum concurrunt ad causandum actum volendi, ita quod actus volendi est a voluntate et ab obiecto cognito ut a causa effectiva" Lect., II, d. 25, 69 (XIX, 253)

37 INGHAM, Mary Beth, «La genèse de la volonté rationnelle: de la Lectura à la Reportatio II, 25» in Duns Scot à Paris 1302-2002, Actes du colloque de Paris, 2-4 septembre 2002, Brepols 2004, 409-423. 
subjectivo e limitado, e o bem objectivo, que em Deus é absoluto e ilimitado, e nas demais criaturas possui também um valor independente de conveniências circunstanciais. Ou seja, a vontade, na autodeterminação do seu exercício, não é inevitavelmente escrava dos seus impulsos, mas tem a capacidade de sair de si mesma e fazer justiça ao bem objectivo enquanto tal, isto é, afirmá-lo sem submetê-lo à estreiteza da própria conveniência. A esta racionalidade ou sensatez primordial da vontade Escoto chama affectio iustitiae, que se pode traduzir por «afecto ou amor justo». Mas a vontade, como simples apetite ou tendência natural, busca também a sua própria perfeição subjectiva, o que a faz considerar os objectos do seu amor à nova medida da própria utilidade. Escoto chama a esta tendência affectio commodi, afecto ou amor de conveniência, de concupiscência. O importante é pôr ordem no amor ${ }^{38}$. É o princípio do amor ordenado onde a afeição justa regula e modera a afeição pelo cómodo, o amor inferior ou mais limitado ${ }^{39}$.

\section{Bibliografia}

ADAMS, Marilyn McCord, "Duns Scotus on the will as rational power", in Via Scoti Methodologica ad mentem Ioannis Duns Scoti, Roma 1995, 839-854.

ALLUNTIS, Félix, Obras del Doctor Sutil Juan Duns Escoto, Cuestiones Cuodlibetales, BAC, Madrid 1968.

BERTONI, Efrem, Duns Scot Filosofo, Società Editrice Vita e Pensiero, Milano 1966.

BONANSEA, Bernardine, "Duns Scotus' voluntarism" in RYAN, John K. - BONANSEA, Bernardine M., John Duns Scotus, 1265-1965, The Catholic University of América Press, Washington 1965, 81-121.

BOLER, J., "Transcending the Natural: Duns Scotus on the Two Affections of the Will" in American Catholic Philosophical Quarterly 67 (1993) 109-126.

FRANK, William A., John Duns Scotus' Quodlibetal Teaching on the will, Washington 1982.

GEMELLI, Agostinho, O Franciscanismo, Ed. Vozes, Petropólis 1944.

GILSON, Étienne, Jean Duns Scot, Introduction à ses positions fondamentales, Librarie Philosophique Vrin, Paris 1952.

38 Ord. IV, d. 49, q. 5, n. 3 (Ed. Vivès XXI 173a): "Nobilior autem secundum rationem est affectio iustitiae affectione commodi, quia regulatrix eius et moderatrix secundum Anselmum, et propria voluntati in quantum libera est, cum affectio commodi esset eius, etiamsi voluntas libera non esset." Sobre a temática do "amor ordenado" em Santo Agostinho, veja-se a título de exemplo ARENDT, Hannah, $O$ conceito de Amor em Santo Agostinho, Ensaio de interpretação filosófica, Ed. Piaget, Lisboa 1997, 39-44.

39 Cf. ArmelladA, Bernardino de, "El mensaje social del beato Juan Duns Escoto" in Naturaleza y Gracia XLI (1994) 364. 
INGHAM, Mary Beth, «La genèse de la volonté rationnelle: de la Lectura à la Reportatio II, 25» in Duns Scot à Paris 1302-2002, Actes du colloque de Paris, 2-4 septembre 2002, Brepols 2004, 409-423.

LEE, S., "Scotus on the Will: the rational Power and the Dual Affections» Vivarium 36/1(1998)40-51.

NOONE, Timothy - ROBERTS, H. Francis, “John Duns Scotus' Quodlibet, a brief study of the manuscripts and an edition of question 16" in SCHABEL, Christopher, Theological Quodlibeta in the Middle Ages, Brill, Leiden-Boston 2007, 131-198.

PÉREZ-ESTÉVEZ, Antonio, "Liberdade divina, possibilidad y contingencia en Duns Escoto", in Veritas 50(2005)3, 85-93.

POPPI, A., "Duns Scoto" in Enciclopedia Filosófica

WILliams, T., The Cambridge Companion to Duns Scotus, Cambridge University Press, Cambridge 2003.

WOLTER, A. B., "Native freedom of the Will as a key to the Ethics os Scotus" in ID. The Philosophical theology of John Duns Scotus, 148-162.

\title{
RESUMO
}

Sendo a inteligência e a vontade partes integrantes da alma, não se opõem, mas colaboram na felicidade do homem. Na sequência dos seus mestres, e da escola franciscana, Escoto dá prioridade, na ordem da execução, à vontade sobre a inteligência, sem que com isso se diminua o papel da razão que é condição sine qua non da vontade. Uma condição prévia e necessária, dado que sem saber não há querer, e quem quer, quer alguma coisa que a inteligência dá a conhecer como objecto. De modo particular a inteligência torna patente o fim da volição, que é o bem infinito. Definida a vontade como "apetite racional livre", o tender livremente, e por isso de modo contingente para o bem, segundo a recta razão, ela não pode ser violentada, ainda que tenha de ser ordenada por uma afeição pela justiça.

\begin{abstract}
Since intelligence and will are component parts of the soul, they do not oppose, but collaborate in the happiness of man. In the sequence of their masters and the franciscan school, Scotus gives priority, in the execution order, to the will over the intelligence, without diminishing the role of the reason which is a sine qua non condition of the will. A previous and necessary condition, since without knowing there is no want, and the one who wants, wants something that intelligence gives to know as an object. In a particular way intelligence makes clear the end of volition, which is the infinite good. Being the will defined as "free rational appetite", the freely tendency, and therefore in contingent way for the good, according to the right reason, it can not be violated, even if it has to be ordained by an affection for justice.
\end{abstract}

